\title{
EXPERIMENTAL AND NUMERICAL INVESTIGATION OF SAND COMPRESSION PECULIARITIES
}

\author{
$\check{S ̆ a r u ̄ n a s ~ S k u o d i s ~}^{1}$, Arnoldas Norkus ${ }^{2}$, Liudas Tumonis ${ }^{3}$, Jonas Amšiejus ${ }^{4}$, Česlovas Aksamitauskas ${ }^{5}$ \\ ${ }^{1,2,3,4}$ Department of Geotechnical Engineering, Vilnius Gediminas Technical University, \\ Saulètekio al. 11, LT-10223 Vilnius, Lithuania \\ ${ }^{5}$ Department of Geodesy and Cadastre, Vilnius Gediminas Technical University, \\ Sauletekio al. 11, LT-10223 Vilnius, Lithuania \\ E-mails: ${ }^{1}$ Sarunas.Skuodis@vgtu.lt (corresponding author); ${ }^{2}$ Arnoldas.Norkus@vgtu.lt; \\ ${ }^{3}$ Liudas.Tumonis@vgtu.lt; ${ }^{4}$ Jonas.Amsiejus@vgtu.lt; ${ }^{5}$ Ceslovas.Aksamitauskas@vgtu.lt
}

Received 30 May 2011; accepted 06 June 2012

\begin{abstract}
Investigation of the compression properties of Klaipeda sand by oedometric testing and numerical modeling is presented. Klaipeda sand is characteristic of the Baltic seashore region sand. Experimental investigation was performed with fraction corresponding to diameter variation bounds of 0.6 and $0.425 \mathrm{~mm}$. Compression test was realized with initial maximal void ratio $\left(e_{0}=0.800\right)$ of sand. Employed vertical stress ramp value is $800.0 \mathrm{kPa} / \mathrm{min}$, maximum loading $\sigma_{\max }=400.0 \mathrm{kPa}$. Applying loading within the range of 50.0 to 120.0 , two vertical stress jumps have been identified. A rubber sample compression test has been performed aiming to deny an assumption, that vertical stress jumps are influenced by device construction. Experiment viewed that not any vertical stress jumps have been recognized. Numerical simulation yielded exactly the same two vertical stress jumps found by compression with oedometer. It proves that the nature of rearrangement of sand grains has been properly reflected by modeling compaction process by DEM. Sand compaction velocity is higher versus applied vertical stress ramp. This is the reason for appearing of the vertical stress jumps. Numerical simulation viewed that location of the largest compression in oedometer is at the top of the sample.
\end{abstract}

Keywords: sand compression, oedometer test, discrete element method (DEM), numerical simulation, morphological parameters.

\section{Introduction}

An analysis of actual deformed behaviour stages of ground in many cases is possible only by applying simulation results at the level of soil particles or grains. Such an approach is important not only for rational, sometimes being in conflict to routine design procedures, employing the partial coefficients of safety. This is also important for identifying the real bearing capacity and deformable response of geotechnical structures, especially for complicated ones.

Still one can state, that numerical simulation of deformed behaviour of soil even at the level of particles can lead to contradictory and unreliable results. Therefore it should be accompanied by some experimental investigation of soil behaviour and proper validation of results. This is necessary for accurate identifying of mechanical properties for numerical modeling, also when applying DEM with large computer resources or widely employed FEM with less computer resources.

The Discrete Element Method (DEM) introduced by Cundall (1974) and Cundall and Strack (1979) is a numerical method used to compute the stresses and displacements in a volume containing a large number of particles such as grains of sand. The granular material is modeled as an assembly of rigid particles and the interaction between each particle is explicitly considered. DEM could be viewed as a generalized finite element method (FEM).

The aim of the current investigation is to analyse the sand compression via oedometer testing and simulating analogous process by applying DEM techniques. Validation of experimental and numerical results, also necessary interventions for corrections due to identified reasons of inaccuracies for creating proper numerical physical model of compression test leads to proper accuracy of numerical modeling.

The reader can be referred to many investigations on comparison of experimental (physical) investigation and adequate numerical modeling of tests (Cheng et al. 2009; Ferellec, McDowell 2010; Kruggel-Emden et al. 2008; Sukumaran et al. 2008; Zhu et al. 2008), but many of them do not sufficiently evaluate the actual shapes of soil particles for deformable behaviour and/or peculiarities of testing equipment. The investigation via DEM in Lithuania is in its primary stage (Amšiejus et al. 2010; Balevičius et al. 2006; Kačianauskas et al. 2010; Pocius, Balevičius 2012).

For creating relevant physical models of actual sand grains, the extended microscopic analysis and relevant 
processing of results should be performed at first (see Maeda et al. 2009; Szarf et al. 2009; Tsomokos, Georgiannou 2010). Such primary investigations prescribe the parameters of particles to be considered (Cavarretta 2009), namely: particle shape, form coefficient, area, perimeter, roundness, angularity and sphericity. The friction between individual particles should be also properly evaluated (Chandler, Sands 2010).

In this investigation we employed the air-dry Klaipeda sand particles with diameters varying within bounds of 0.6 and $0.425 \mathrm{~mm}$. This corresponds to one fracture, obtained by performing usual sieve analysis. This fracture was the dominating and prescribing compressibility of Klaipeda sand (Skuodis, Amšiejus 2011). Such an approach with analysis of one fracture was applied aiming to reduce the number of unknowns (Arasan et al. 2011), id est, for reducing computational time of DEM simulations. The physical and numerical experiments have been started with maximal initial void ratio soil aiming to investigate nature of compaction processes during loading (Thewes et al. 2010). Current numerical investigations have been performed by applying DEM software "EDEM 2.2.1" (DEM solutions 2009) and FEM software "Plaxis 3D Foundation" (Plaxis 2007). Physical experiments have been performed by applying universal oedometer apparatus ADS 1/3 (Wille Geotec Group 2010).

\section{Experimental set-up}

Baltic Sea sand from the area of Klaipeda was chosen because of naturally larger smoothness and size of grains.

The sieve analysis according to standards ISO3310:2-1999 and BS410-1:2000 has been performed. The fraction of $0.6-0.425 \mathrm{~mm}$ grains was employed for further investigations. For avoiding water influence on interaction of grains, the air- dry sand has been used.

The microscopic analysis of grains shapes for selected fraction has been performed (Kavrus, Skuodis 2012) for identifying morphological parameters of grains. The scanning electronic microscope and specialized software for processing of views "STIMAN" (STIMAN 2010) have been employed. The view analysis of microscopic investigations yielded the following morphological parameters of sand grains: roundness $C=\left(2(\pi A)^{0.5}\right) / P$ (where $A$ is area of a particle, $\mu \mathrm{m}$ ); sphericity $R=(d / D)^{0.5}$ (where $d$ is internal particle diameter, $\mu \mathrm{m}$ and $D$ is external particle diameter, $\mu \mathrm{m}$ ) and form coefficient $K_{f}=a / b$ (where $a$ is internal particle diameter, $\mu \mathrm{m}$ and $b$ is external particle diameter, $\mu \mathrm{m}$ ).

Processing data of 33 grains of sand yielded the mi$\operatorname{nimum}\left(K_{f, \min }=0.3413\right)$, maximum $\left(K_{f, \max }=0.8808\right)$ and mean $\left(K_{f, \text { mid }}=0.6970\right)$ form coefficients for physical models of particles.

Compression test has been performed by universal oedometer apparatus ADS 1/3 (Wille Geotech Group 2010), see Fig. 1. The poured via free fall soil was applied aiming to make identical conditions for numerical and physical experiments. Such an approach to sample preparations for physical experiments yielded the maximal initial void ratio $e_{o}=0.800$.

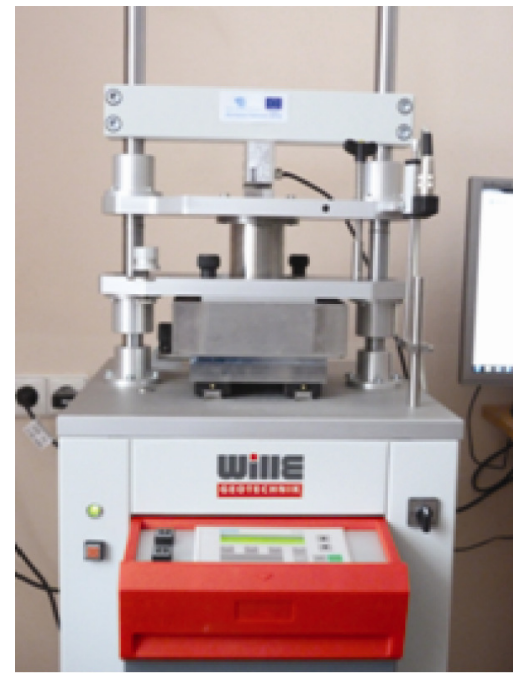

Fig. 1. Universal oedometer apparatus ADS 1/3 (Wille Geotec Group 2010)

Amongst negative side effects met when preparing the compression test is creating a contact between soil and porous stone (compressing stamp) of oedometer. Obviously, the vertical pressure on top of soil sample is not a zero value. Thus, one cannot exactly identify the initial void ratio $e_{o}$ of sample (Amšiejus et al. 2006). Note, that discrete model for simulation is free from this side effect.

To check an influence of loading velocity (rate), the particles of fraction $(0.6-0.425 \mathrm{~mm})$ have been loaded with different velocities, namely: $25.0 ; 50.0 ; 100.0$; $200.0 ; 400.0$ and $800.0 \mathrm{kPa} / \mathrm{min}$. All velocities resulted in the same character of compression curve. Therefore all experiments further have been performed with $800.0 \mathrm{kPa} / \mathrm{min}$ loading rate. This rate, the maximal available for employed testing equipment was also used for numerical simulation of compression (compaction) test.

The maximal loading value of $400.0 \mathrm{kPa}$ was taken for ensuring only compaction and for avoiding crash of separate sand particles. The average duration of compaction test was $30 \mathrm{sec}$; results have been fixed with $0.5 \mathrm{sec}$ intervals.

\section{DEM simulation}

Numerical simulation of compression test has been simulated by applying discrete element method (DEM). The method is applied for modeling of noncohesive grained material. The DEM analysis method "EDEM 2.2.1 Academic code" (DEM solutions 2009) has been employed for simulations.

A method of parametric reduction is applied rather often as performing test for actual sample dimensions requires large computational resources and time.

Therefore, the reduced sample dimensions employed for numerical simulations were as follows: height $h=0.005 \mathrm{~m}$, diameter $\varnothing=0.01 \mathrm{~m}$. The dimensions of particles filled into the volume remained as of original ones (see Fig. 2). 


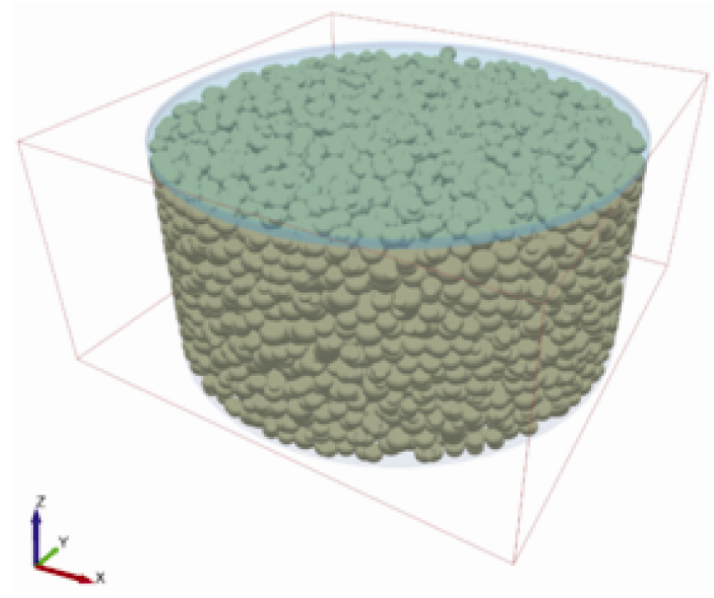

Fig. 2. Discrete model of oedometer and sample

For more accurate description of shape of grains (e.g. spherical shape of particle is the most rough discretization), the grain shape model was created applying the multi-sphere (MS) approach. This approach allows creating the discrete model of actual sand grain as a compound of a clump of spheres of different radii. In our case discrete models of grains consisted of 3-5 spheres.

Three characteristic MS particles (see Fig. 3) with different morphological parameters (see Table 1) have been created by processing morphological parameters obtained via microscope view analysis with software "STIMAN" (STIMAN 2010).

The following physical parameters of discrete model of particles were chosen for numerical simulations, namely: Poisson's ratio $v=0.14$, density $\rho=2650 \mathrm{~kg} / \mathrm{m}^{3}$, shear modulus $G=3.1 \mathrm{e}+07 \mathrm{~Pa}$, coefficient of restitution 0.5 , coefficient of static friction 0.3 , coefficient of rolling friction 0 . Shear modulus was also reduced due to limited computational resources, respectively.
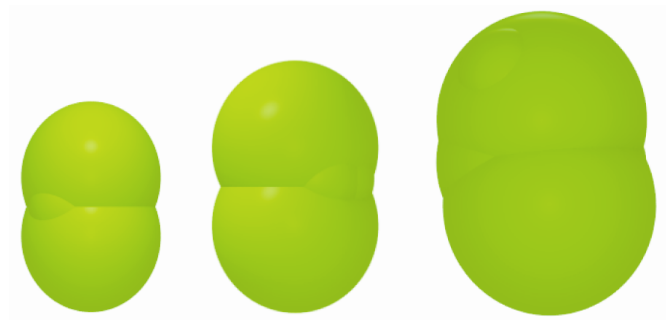

Fig. 3. Characteristic shapes of modeled particles

Table 1. Parameters of created discrete models of particles

\begin{tabular}{c|c|c|c}
\hline & $\begin{array}{c}\text { Mass, } \\
\mathrm{kg}\end{array}$ & $\begin{array}{c}\text { Volume, } \\
\mathrm{m}^{3}\end{array}$ & $\begin{array}{c}\text { Total number } \\
\text { of particles }\end{array}$ \\
\hline Particle 1 & $7.308 \mathrm{E}-08$ & $2.758 \mathrm{E}-11$ & 2310 \\
\hline Particle 2 & $1.036 \mathrm{E}-07$ & $3.908 \mathrm{E}-11$ & 2309 \\
\hline Particle 3 & $1.975 \mathrm{E}-07$ & $7.451 \mathrm{E}-11$ & 1101 \\
\hline
\end{tabular}

The particles were created randomly setting them to the larger volume than created oedometer. Then particles were dropped into oedometer via gravity force. Surface flattening was performed until it reached oedometer's height by controlled mass of the particles and this process did not affect initial porosity.

The maximum magnitude of initial void ratio $e_{o}=0.668$ has been obtained by filling procedures.

At the second stage the filled particles have been compressed. Duration of numerical experiment was $t=0.3 \mathrm{~s}$. with the linearly constant velocity $v=0.00075 \mathrm{~m} / \mathrm{s}$ of porous stone (compressing plate).

Selected simulation time step was $1 \mu \mathrm{s}$. The total duration of numerical experiment was 18.3 hours.

Analogous modeling of oedometer and that of process of compression have been performed by "Plaxis $3 \mathrm{D}$ Foundation" finite element method (FEM) software (Plaxis 2007). The following soil parameters have been employed: void ratio $e=0.798$; deformation modulus $E_{\text {oed }}=58.6 \mathrm{MPa}$; Poisson's ratio $v=0.270$; unit weight $\gamma=14.56 \mathrm{kN} / \mathrm{m}^{3}$; angle of internal friction $\varphi=33^{\circ}$; cohesion $c=12.0 \mathrm{kPa}$. Internal friction angle and cohesion values were taken by processing simple shearing tests results of investigated sand of Klaipeda.

\section{Analysis of results}

The view analysis of microscopic investigations yielded the following morphological parameters of sand grains: roundness $C=0.49$; sphericity $R=0.79$; form coefficient $K_{f}=0.697$ (see Fig. 4).

When analyzing Fig. 4, one can find that some particles (due to the diameters) are larger or less than the mesh of sieves. This phenomenon can be explained as follows: the oblong particles get through mesh of sieves (Žurauskienè et al. 2010), therefore they appear in other fractions of investigated sand.

When comparing the results of numerical and physical experiments, the following features have been identified, namely:

1. The maximum void ratio of numerical experiment $\left(e_{o}=0.668\right)$ is less comparing it by physical experiment $\left(e_{o}=0.800\right)$.

2. The created discrete models of soil grains fit the morphological parameters obtained by microscopic analysis. But the actual shape of discrete models of grains (see Fig. 4) differs from the actual shapes of grains (see Fig. 5).

3. The stress jumps have been observed at certain time points when performing compression tests, both numerically and physically.

When analyzing some discrepancy between maximum initial void ratios, it is obvious that the simulated mixture of discrete models of grains for numerical simulations is not completely the same when comparing it with the natural mixture, corresponding one fracture (0.6-0.425 mm, obtained from sieve analysis). It is obvious that the sand fracture mixture, containing relatively much larger particles in diameter, results in lower initial void ratio (Skuodis, Amšiejus 2011).

One can also state that the actual surface of discrete models of particles is more smooth and soft when compared with actual ones of sand grains. 


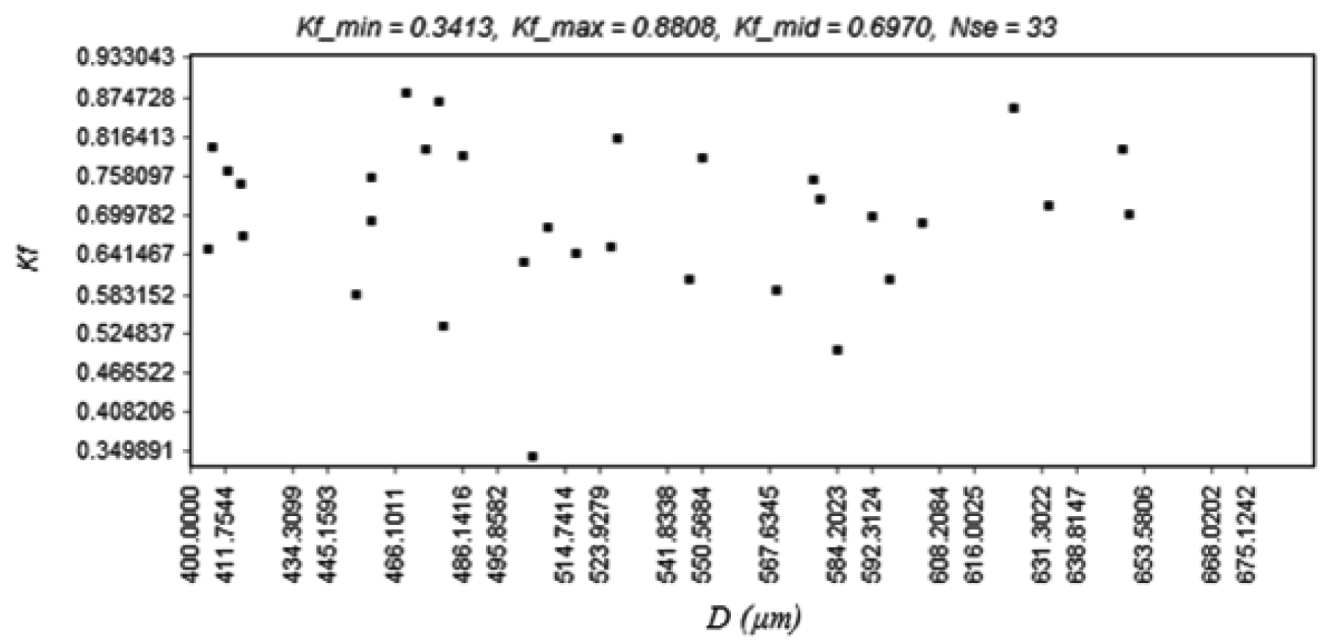

Fig. 4. Distribution of form coefficient versus particle diameter for characteristic Baltic seashore sand

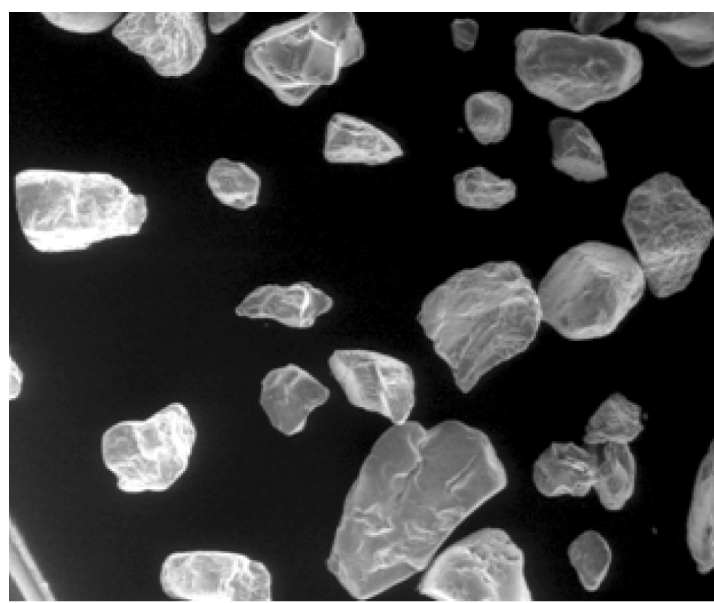

Fig. 5. Characteristic shapes of the Baltic seashore sand

The stress jumps of vertical pressure were observed both in numerical and physical tests. Theoretically, the compressed soil sample during physical test had to be loaded by constantly increasing load, id est, by $800.0 \mathrm{kPa} / \mathrm{min}$ (Fig. 6), but one observed the maximum jumps of vertical load within an interval of 50.0$120.0 \mathrm{kPa}$.

When results are plotted using vertical stress versus vertical strain diagram (see Fig. 7), it explains the results of Fig. 6.

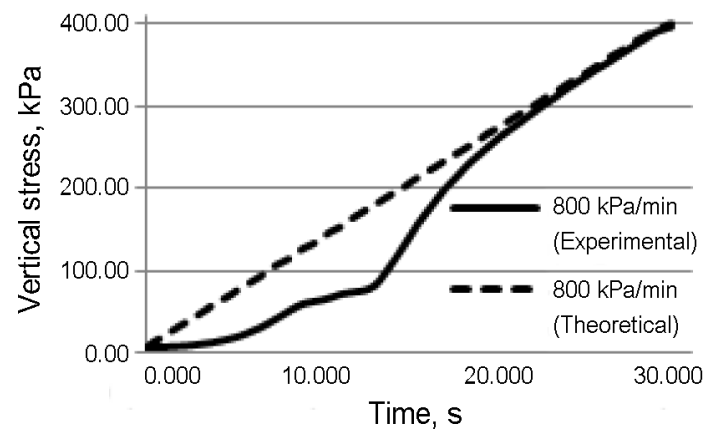

Fig. 6. Controlled vertical stress ramp $(800.0 \mathrm{kPa} / \mathrm{min})$ versus time

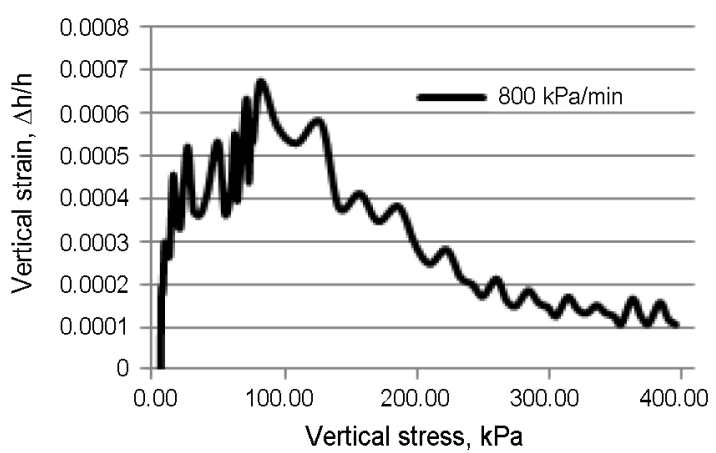

Fig. 7. Vertical stress versus vertical strain $(800.0 \mathrm{kPa} / \mathrm{min})$

Analyzing the results of Fig. 7 it was observed that when vertical stress is less than $200 \mathrm{kPa}$, vertical strain values increase. When vertical stress is between 200 and $400 \mathrm{kPa}$, vertical strain values stabilize and vertical stress ramp becomes equal to theoretical. This process depends on initial soil sample void ratio. Vertical strain values increase when soil sample void ratio is high. When soil density increases, then vertical strain values decrease.

The direction line, created according to loading velocity and load application time, shows that loading velocity was not linear (Fig. 8). In case of homogeonous material the direction line corresponds to the horizontal one.

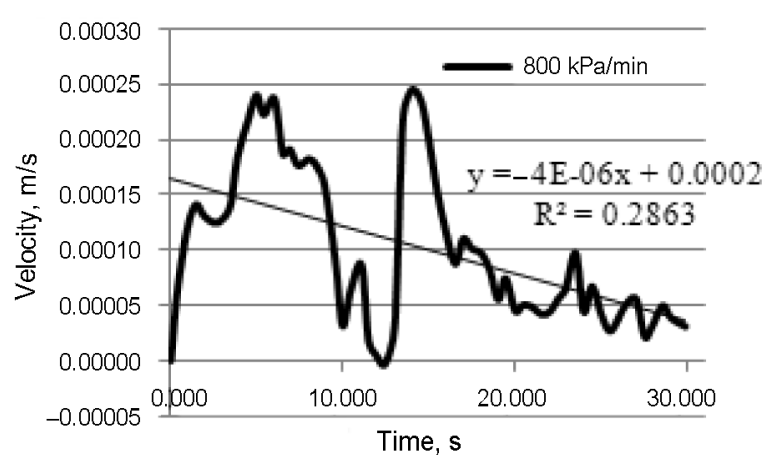

Fig. 8. Vertical stress ramp velocity versus vertical stress loading time 
The jumps of vertical pressure have been identified by compressing soil with different rates: $25 ; 50 ; 100 ; 200$ and $400 \mathrm{kPa} / \mathrm{min}$ (see Figs 9-13).

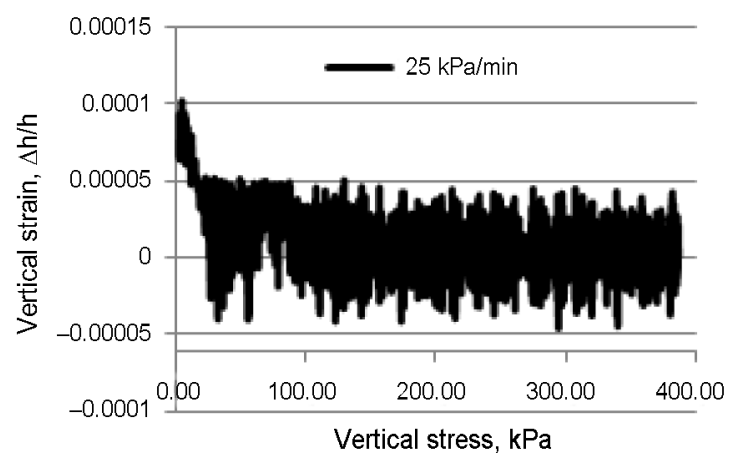

Fig. 9. Vertical stress versus vertical strain $(25.0 \mathrm{kPa} / \mathrm{min})$

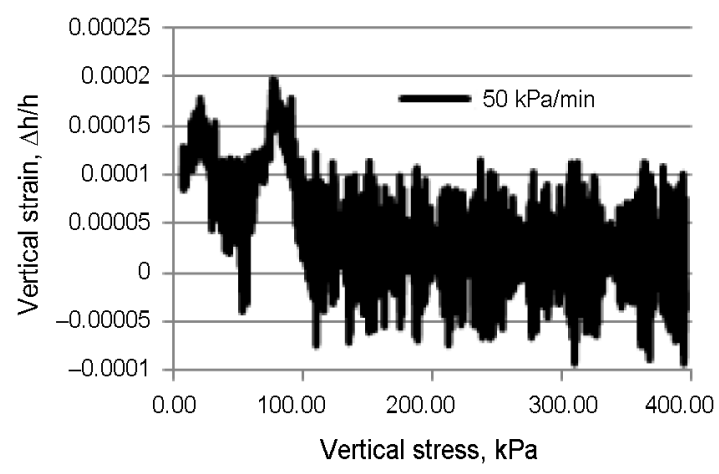

Fig. 10. Vertical stress versus vertical strain $(50.0 \mathrm{kPa} / \mathrm{min})$

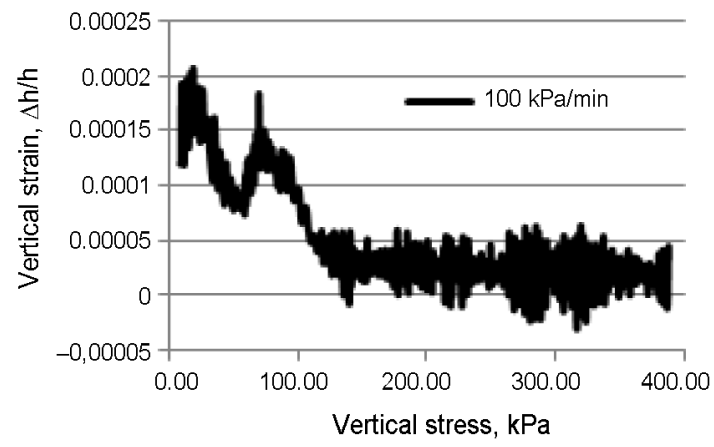

Fig. 11. Vertical stress versus vertical strain $(100.0 \mathrm{kPa} / \mathrm{min})$

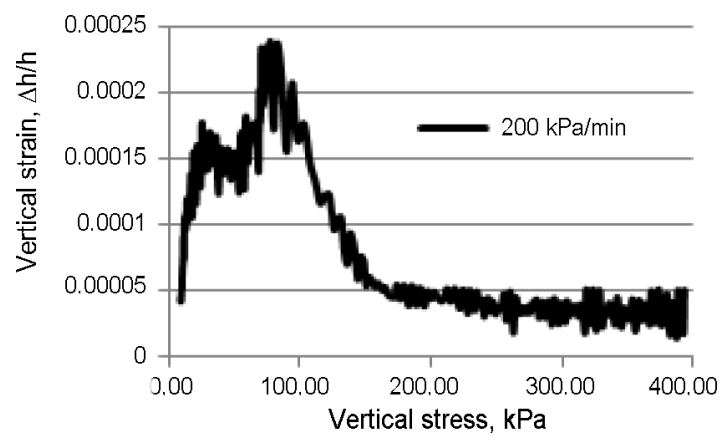

Fig. 12. Vertical stress versus vertical strain $(200.0 \mathrm{kPa} / \mathrm{min})$

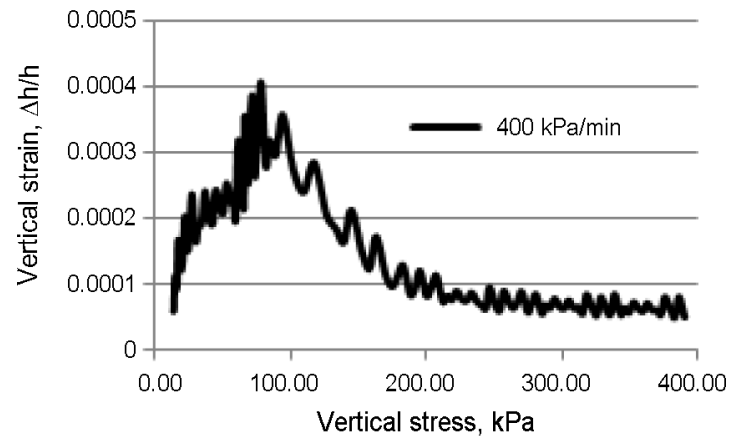

Fig. 13. Vertical stress versus vertical strain $(400.0 \mathrm{kPa} / \mathrm{min})$

Basing on analysis results of Fig. 7 and Figs 9-13, one can state that vertical stress jumps are induced by loading velocity. Aiming to reject the influence of technical reasons or technical peculiarities of testing equipment, an additional compression test was performed with rubber sample under loading velocity of $100 \mathrm{kPa} / \mathrm{min}$. The loading interval within 50.0 and $120.0 \mathrm{kPa}$ was analyzed (see Figs 14 and 15).

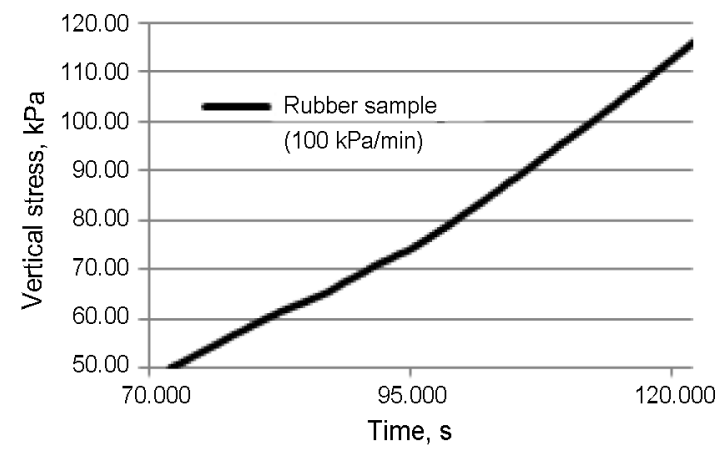

Fig. 14. Controlled vertical stress ramp (rubber compression from 50.0 to $120.0 \mathrm{kPa}$ ) versus time

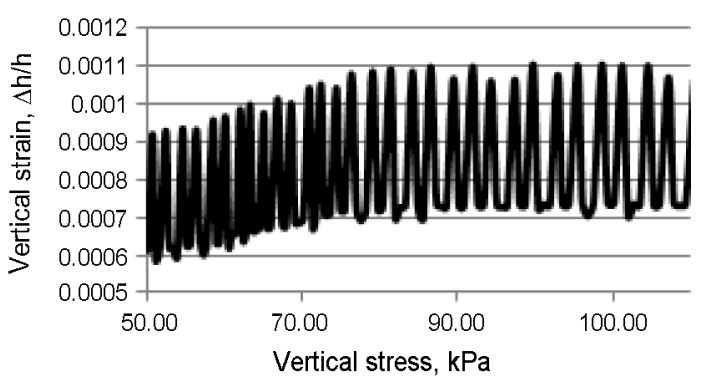

Fig. 15. Vertical stress versus vertical strain (rubber compression from 50.0 to $120.0 \mathrm{kPa}$ )

When comparing compression tests with rubber and soil (see Figs 7 and 15) one can state that the reason of loading jumps is different due to technical peculiarities of oedometer. The appeared stress change on the top of the sample is induced by sudden change of soil structure, id est, the velocity of rearrangement of soil grains is larger comparing with load application velocity. Therefore the load transducer is fixing stress change on the top of soil sample.

When performing soil compression test numerically, one faces the analogous phenomenon, id est, the results 
are similar. The loading is described via relative (normalized) units in numerical model which are different from real experiment. Such an approach (also in respect of physical parameters) is widely used currently by many researchers aiming to reduce computational resources, as was described above. Thus, the compression results obtained via numerical simulation (see Figs 16 and 17) are compared with those obtained via actual (physical) experiments qualitatively, aiming to identify the character of compressive curve.

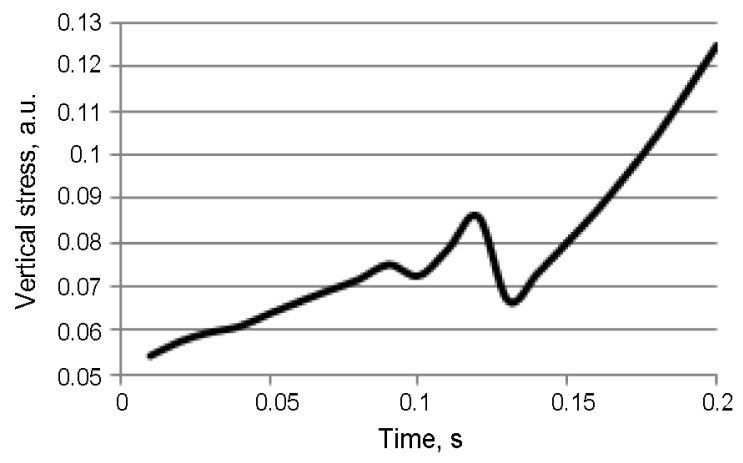

Fig. 16. Characteristic sand compression curve via DEM simulation

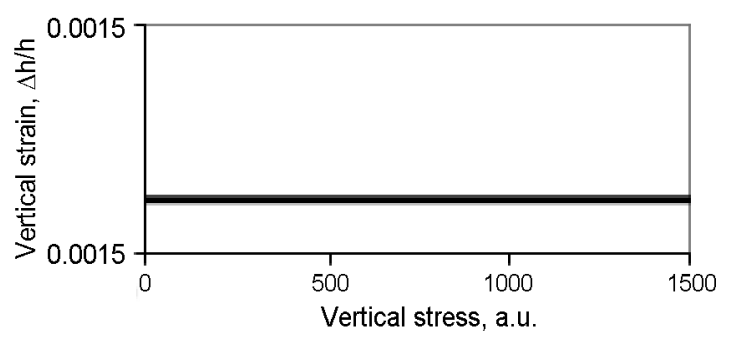

Fig. 17. Vertical stress versus vertical strain via DEM simulation

When analyzing Figs 7 and 17 one can find that soil particles displace in respect of each other during the compression process. This induce the stress jumps under the porous stone. When performing the physical (experimental) tests, the soil was applied incrementally under constant velocity $(800.0 \mathrm{kPa} / \mathrm{min})$ with increasing load. When performing numerical simulations the load velocity $(v=0.00075 \mathrm{~m} / \mathrm{s})$ was constant during the test time.

Fig. 18 shows the view of inter-particle velocities flow of numerical test model. This model was created to analyze reasons of stress changes within sample in oedometer.

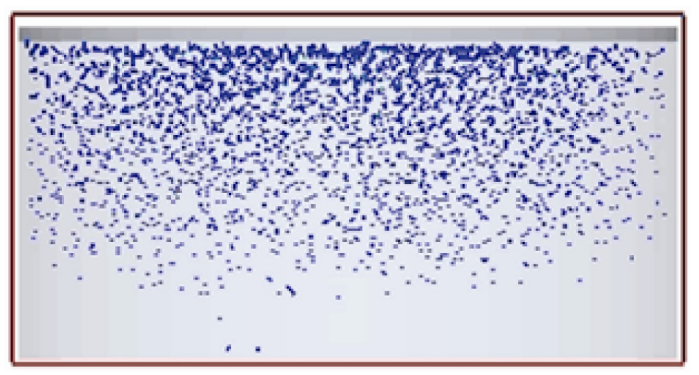

Fig. 18. Particle flow velocity in oedometer
Fig. 18 clearly illustrates that maximum rearrangement of particles is located on the top of oedometer sample in soil, id est, under the porous stone. This interparticle movement process proves that the velocity of particles when loaded becomes larger (when friction of particles is overcome) compared with velocity of applied loading.

The same compression curve character was obtained having simulated the oedometer and the soil (parameters compatible with the simulated by DEM) by FEM "Plaxis 3D Foundation" (Plaxis 2007), Fig. 19.

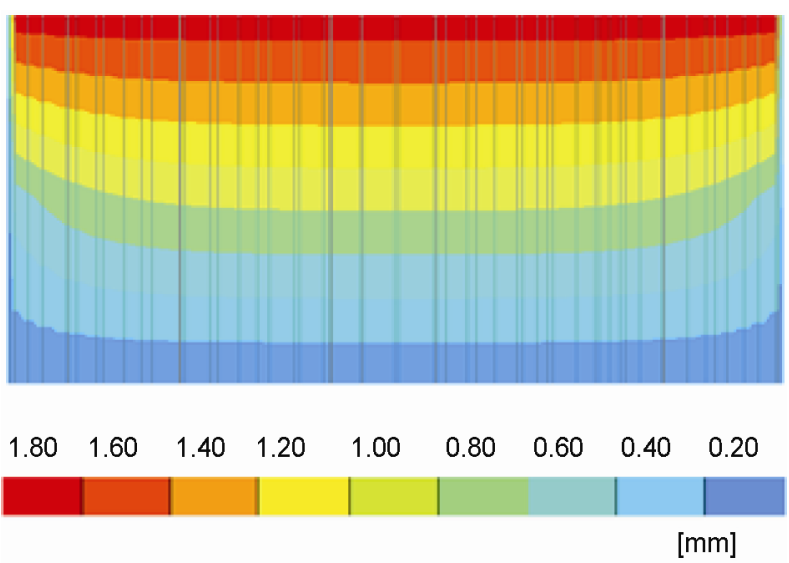

Fig. 19. Total displacement distribution in oedometer

When analyzing Fig. 19, one also can find that maximum displacements of soil are at pore stone, compressing the soil sample. The displacements are significantly less near oedometer walls because of the developed friction between soil and walls. The analogous results have been also obtained from DEM analysis by software "EDEM 2.2.1" (see Fig. 18).

\section{Conclusions}

1. Despite the fact that the shape of developed discrete models of sand particles fits the form coefficients (determined via microscopic analysis) of actual sand grains, they are not identical to the natural sand ones. This results in different actual and simulated maximal void ratios, they are $e_{o}=0.800$, and $e_{o}=0.668$, respectively.

2. The nature of stress jumps, identified experimentally can be explained by the results of numerical simulations. When inter-particle friction is overcome, the velocity of rearrangement of particles is larger than the loading velocity. When the loading reaches the $120 \mathrm{kPa}$ limit, the velocity of rearrangement of particles reduces significantly and the movement of particles practically stops.

3. During experimental investigations vertical stress jumps are induced by loading velocity. Aiming to avoid vertical stress jumps it is recommended to do experimental tests with lower than $50 \mathrm{kPa} / \mathrm{min}$ vertical stress ramp.

4. Results of numerical simulations proved that the largest compaction is at the top of sample, id est, at location of largest rearrangement of soil particles. 
5. Although the nature of compression (compaction of particles) was identified, one should perform numerical simulations with more than two morphological parameters (form coefficient $K_{f}$ and particle diameter $D$ ) of soil grains and, due to the computational possibilities, to perform simulation with closer to actual physical parameters. Such an approach could enable comparing the results of numerical simulation and physical experiment not only qualitatively.

Generalizing the findings of current investigation it can be stated that analysis and qualitative comparison of numerical simulation and physical experiments yielded that numerical simulation adequately describes the nature of compaction processes during compression test. It also allows to evaluate adequately the actual boundary conditions. DEM also allows to qualitatively and quantitatively evaluate the relevant application of FEM and choosing its proper physical parameters. Still, it should be emphasized, that numerical simulation requires performing primary validation of numerical simulation and physical experiments aiming to calibrate initial parameters for adequate evaluation of the boundary conditions.

\section{Acknowledgement}

Equipment and infrastructure of Civil Engineering Scientific Research Center of Vilnius Gediminas Technical University was employed for investigations.

\section{References}

Amšiejus, J.; Kačianauskas, R.; Norkus, A.; Tumonis, L. 2010. Investigation of the sand porosity via oedometric testing, The Baltic Journal of Road and Bridge Engineering 5(3): 139-147. http://dx.doi.org/10.3846/bjrbe.2010.20

Amšiejus, J.; Mackevičius, R.; Medzvieckas, J.; Sližytè, D.; Stragys, V. V. 2006. Gruntu fizinès ir mechanines savybes: laboratoriniai darbai [Soil physical and mechanical properties, Laboratory testing]. Vilnius: Technika. $164 \mathrm{p}$. (in Lithuanian).

Arasan, S; Akbulut, S.; Hasiloglu, A. S. 2011. Effect of particle size and shape on the grain size distribution using image analysis, International Journal of Civil and Structural Engineering 1(4): 968-985.

Balevičius, R.; Džiugys, A.; Kačianauskas, R.; Maknickas, A.; Vislavičius, K. 2006. Investigation of performance of programming approaches and languages used for numerical simulation of granular material by the discrete element method, Computer Physics Communications 175(6): 404415. http://dx.doi.org/10.1016/j.cpc.2006.05.006

BS410-1:2000. Test sieves. Technical requirements and testing. Part 1: Test sieves of metal wire cloth. British Standard Sieve Series. $16 \mathrm{p}$.

Cavarretta, I. 2009. The influence of particle characteristics on the engineering behavior of granular materials: $\mathrm{PhD}$ thesis. London: London Imperial College.

Chandler, H. W.; Sands, C. M. 2010. Including friction in the mathematics of classical plasticity, International Journal for Numerical and Analytical Methods in Geomechanics 34(1): 53-72.

Cheng, S.; Bryant, R.; Doerr, S. H.; Rhodri Williams, P.; Wright, C. J. 2009. Application of atomic force microsco- py to the study of natural and model soil particles, Journal of Microscopy 231(3): 384-394.

http://dx.doi.org/10.1111/j.1365-2818.2008.02051.x

Cundall, P. A. 1974. A computer model for rock-mass behaviour using interactive graphics for the input and output of geometric data. Rep. AD/A-001 602, U.S. National Technical Information Service.

http://dx.doi.org/10.1680/geot.1979.29.1.47

Cundall, P. A.; Strack, O. D. L. 1979. A discrete numerical model for granular assemblies, Geotechnique 29(1): 4765.

DEM Solutions. 2009. EDEM v2.2. Edinburgh, UK: DEM Solutions Ltd.

Ferellec, J.-F.; McDowell, G. R. 2010. A method to model realistic particle shape and inertia in DEM, Granular Matter 12: 459-467.

http://dx.doi.org/10.1007/s10035-010-0205-8

ISO3310-2:1999. Test sieves. Technical requirements and testing. Part 2: Test sieves of perforated metal plate. International Organization for Standardization. $10 \mathrm{p}$.

Kačianauskas, R.; Maknickas, A.; Kačeniauskas, A.; Markauskas, D.; Balevičius, R. 2010. Parallel discrete element simulation of polydispersed granular material, Advances in Engineering Software 41(1): 52-63.

http://dx.doi.org/10.1016/j.advengsoft.2008.12.004

Kavrus, A.; Skuodis, Š. 2012. Smèlinių gruntų morfologinių parametru nustatymas [Investigation of morphological parameters for sand soil], in Proc. of the 15th Conference for Junior Researchers "Science - Future of Lithuania", 22-24 May, 2012, Vilnius, Lithuania (in Lithuanian). Available from Internet:

http://jmk.sf.vgtu.lt/index.php/jmksf/jmksf15/paper/viewF ile/14/6

Kruggel-Emden, H.; Rickelt, S.; Wirtz, S.; Scherer, S. 2008. A study on the validity of the multi-sphere Discrete Element Method, Powder Technology 188: 153-165. http://dx.doi.org/10.1016/j.powtec.2008.04.037

Maeda, M.; Fukuma, M.; Nukudani, E. 2009. Macro and micro critical states of granular materials with different grain shapes, in Proc. of the 6th International Conference on Micromechanics of Granular Media 1145: 829-832.

Plaxis. 2007. 3D Foundation. Version 2. Delft University of Technology \& Plaxis bv. The Netherlands.

Pocius, G.; Balevičius, R. 2012. Daugiadispersio ir viendispersio daleliu mišinio elgsenos tyrimas. II dalis: Stabilumo būsenuc charakterizavimas [Simulation of the poly- and monodispersed granular material. Part II: the stability characterization], Engineering Structures and Technologies 4(2): 59-66 (in Lithuanian). http://dx.doi.org/10.3846/2029882X.2012.697316

Skuodis, ک̌.; Amšiejus, J. 2011. Skirtingu smèlio frakciju spūdumo tyrimas kompresiniu aparatu [Investigation into the compressibility of different types of sand fractions using a oedometer], Engineering Structures and Technologies 3(1): 16-22 (in Lithuanian). http://dx.doi.org/10.3846/skt.2011.02

STIMAN. 2010. Structural image analysis. Moscow State University. Moscow.

Sukumaran, B.; Das, N.; Ashmawy, A. K. 2008. Modeling granular particle shape using discrete element method, in Proc. of the 1st International FLAC/DEM Symposium, 25-27 August, 2008, Mineapolis. 
Szarf, K.; Combe, G.; Villard, P. 2009. Influence of the grains shape on the mechanical behavior of granular materials, in Proc. of the 6th International Conference on Micromechanics of Granular Media 1145: 357-360.

Thewes, M.; Budach, Ch.; Galli, M. 2010. Laboratory tests with various conditioned soils for tunneling with earth pressure balance shield machines, in $4^{\text {th }}$ BASF TBM Conference in London/GB - Laboratory Tests with conditioned Soils for EPB Tunneling 6: 21-30.

Tsomokos, A.; Georgiannou, V. N. 2010. Effect of grain shape and angularity on the undrained response of fine sands, Canadian Geotechnical Journal 47(5): 539-551. http://dx.doi.org/10.1139/T09-121
Zhu, H. P.; Zhou, Z. Y.; Yang, R. Y.; Yu, A. B. 2008. Discrete particle simulation of particulate systems: a review of major applications and findings, Chemical Engineering Science 63(23): 5728-5770. http://dx.doi.org/10.1016/j.ces.2008.08.006

Žurauskienè, R.; Mačiulaitis, R.; Červokienè, A.; Žurauskas, R. 2010. Medžiagotyra ir statybinès medžiagos: Laboratoriniai darbai [Materials science and construction materials. Laboratory testing manual]. Vilnius: Technika. 92 p. (in Lithuanian).

Wille Geotec Group. 2010. Universal oedometer test device ADS 1/3. Göttingen, Germany.

Šarūnas SKUODIS. PhD student at the Department of Geotechnical Engineering, Vilnius Gediminas Technical University (VGTU), Lithuania. Research interests: modeling mechanical properties of soil, soil - structure interaction, foundation engineering.

Arnoldas NORKUS. Dr, Prof., Head of the Department of Geotechnical Engineering, Vilnius Gediminas Technical University (VGTU), Lithuania. Research interests: soil mechanics, modeling mechanical properties of soil, foundation and construction design.

Liudas TUMONIS. A junior research fellow at the Department of Geotechnical Engineering, Vilnius Gediminas Technical University (VGTU), Lithuania. Research interests: finite element method, discrete element method and other numerical methods applications in soil mechanics and mechanical engineering.

Jonas AMŠIEJUS. Dr, Assoc. Prof. at the Department of Geotechnical Engineering, Vilnius Gediminas Technical University (VGTU), Lithuania. Research interests: mechanical properties of soil, determination of load intensity and deformations in strata.

Česlovas AKSAMITAUSKAS. Dr, Prof., Head of the Department of Geodesy and Cadastre, Vilnius Gediminas Technical University (VGTU), Lithuania. Research interests: engineering structures deformation analysis by geodesy methods. 